\title{
Teams, Team Process, and Team Building
}

James W. Bishop

Dow Scott

Loyola University Chicago, dscott@luc.edu

\section{Stephanie Maynard-Patrick}

Lei Wang

Follow this and additional works at: https://ecommons.luc.edu/business_facpubs

Part of the Business Administration, Management, and Operations Commons, and the Performance Management Commons

\section{Recommended Citation}

Bishop, James W.; Scott, Dow; Maynard-Patrick, Stephanie; and Wang, Lei. Teams, Team Process, and Team Building. Clinical Laboratory Management, 2nd Edition, , : 373-391, 2014. Retrieved from Loyola eCommons, School of Business: Faculty Publications and Other Works, http://dx.doi.org/10.1128/ 9781555817282.ch18

This Book Chapter is brought to you for free and open access by the Faculty Publications and Other Works by Department at Loyola eCommons. It has been accepted for inclusion in School of Business: Faculty Publications and Other Works by an authorized administrator of Loyola eCommons. For more information, please contact ecommons@luc.edu. c) (†) $\ominus$

This work is licensed under a Creative Commons Attribution-Noncommercial-No Derivative Works 3.0 License. (C) ASM Press 2014 


\title{
Teams, Team Process, and Team Building
}

\author{
James W. Bishop, K. Dow Scott, \\ Stephanie Maynard-Patrick, and Lei Wang
}

Have Teams

Common Purpose $\bullet$ Interdependent Tasks •

Summary $\bullet$ A Cautionary Note

Selecting Team Members

Task-Related Training • Team-Related Training

Leading Teams

General Ideas about Leadership: A Brief Review • Leadership in a Team Environment $•$ Team Leader Selection

Motivating Team Performance

Goal Setting and Performance $\bullet$ Goal Setting and

Teams • Evaluating Teams and Team Members $\bullet$ Pros

and Cons of Rewarding Team Members

Virtual Teams

Global Teams

Summary

KEY POINTS

GLOSSARY

REFERENCES

APPENDIXES

Clinical Laboratory Management, 2nd Edition Edited by L. S. Garcia

(C) 2014 ASM Press, Washington, DC

doi:10.1128/9781555817282.ch18

\section{OBJECTIVES}

To define a work team and distinguish it from a work group

To indicate why a precise definition of "team" is important

To explain the concept of group process within teams

To describe the situations in which teams can be productive and those in which they cannot

To define "task interdependence," the types of task interdependence, and their importance; to explain how task interdependence influences choices related to teams

To explain the basic concepts behind selecting team members

To explain the importance of training with respect to teams, distinguish the differences between task-related training and team-related training, and understand the concept of team building

To list the types of leadership associated with teams and the advantages and disadvantages of each

To explain the importance of goals, both individual and team; to explain how team goals can be set and achieved

To explain how to evaluate team and team member performance and emphasize individual performance in terms of contribution to the team

What sets apart high-performance teams ... is the degree of commitment, particularly how deeply committed the members are to one another.

Jon R. Katzenbach and Douglas K. Smith

Deams can be found eVerywhere in organizations. Employees are placed in work teams, task forces, committees, quality improvement teams, safety teams, and teams by a variety of different names. Employees working together is nothing new. In fact, it is the very nature of organizations to put employees into groupings. However, managers, consultants, and academicians make distinctions between employees organized into groups as compared with those who operate as teams. In fact, they point out numerous advantages that are derived from teams. These include increased individual performance, better quality, less absenteeism, improved employee engagement, reduced employee turnover, leaner plant structures, and substantial improvements in production cycle time $(4,14,21)$. In general, teams are considered an important ingredient of organizational success in the modern economy due to needs for rapid information exchange and response to customer demands (16). 
On the other hand, virtually everyone has had negative experiences working in teams or in work groups. Dysfunctional work groups and teams can have a negative impact on employee performance, retention, and morale. These dysfunctions include conflict among team members, social loafing, misdirected goals to satisfy members of the team and not the organization, and poor communication $(8,26,70)$.

This chapter will examine what is involved in creating effective teams first by differentiating between work units and teams, examining team processes, understanding how and when teams can contribute to a more effective organization, and discussing how to select and develop the best team members, develop effective team leadership, and motivate team performance. Then we will examine some of the latest developments and challenges in teams, including virtual and global teams.

\section{Definition of a Team}

There are many definitions of the term "team." These include, but are not limited to:

- A small number of people with complementary skills who are committed to a common purpose and performance goals for which they hold themselves mutually accountable (34)

- A group whose individual efforts result in a performance that is greater than the sum of those individual parts (59)

- Two or more people with different tasks who work together adaptively to achieve specified and shared goals (9)

- A collective of individuals who are interdependent in their tasks, who share responsibility for outcomes, who see themselves and who are seen by others as an intact social entity embedded in one or more larger social systems (for example, business unit or corporation), and who manage their relationships across organizational boundaries (16)
Although teams meet all of the defining characteristics of groups (configurations of more than two interdependent individuals who interact over time), teams incorporate skill differentiation in a context where performance outcomes including rewards or punishments are shared by all team members $(30,34)$. Common to each of the above definitions is the idea of blending different skills to accomplish objectives that individuals, working independently, could not accomplish. Furthermore, implicit in each definition is the idea of both individual and collective accountability. That is, each individual can be rewarded or taken to task for the results of both the team's results and his or her own contribution to the results.

\section{Distinguishing Teams from Work Groups}

The difference between "team" and "group" can be examined from the perspective of synergy. A work group is defined as "a group that interacts primarily to share information and to make decisions to help each member perform within his or her area of responsibility" (59). Thus, a group does not require joint effort. The group's outcomes are the sum of individual members' contributions. A team, on the other hand, generates positive synergy through the coordinated efforts of its members. Team members produce a level of performance that is greater than the sum of individual inputs. Within a work group, members share information, have neutral or even negative synergy, and accountability is at the individual level. Members' skills may or may not complement each other. By contrast, a team is designed for collective performance, synergy among its members should be positive, and accountability is both individual and mutual. Members' skills are complementary to each other, and members of the team help each other to accomplish team goals (59) (see Table 18.1).

\section{Types and Classifications of Teams}

There are various ways to categorize teams. Based on how members allocate their time, teams can be full-time or part-time. Teams can be permanent or temporary. From

Table 18.1 Differences between work groups and teams

\begin{tabular}{|c|c|c|}
\hline & Work group & Team \\
\hline Information sharing & $\begin{array}{l}\text { Information is typically shared between those who } \\
\text { have it and those that need it most; information is } \\
\text { not freely shared with everyone in the work group }\end{array}$ & $\begin{array}{l}\text { Information is shared freely with all members even if } \\
\text { the information does not seem relevant to everyone's } \\
\text { task }\end{array}$ \\
\hline Accountability for outcomes & Accountability at the individual level & $\begin{array}{l}\text { Accountability for the overall outcome is shared by } \\
\text { all team members with often specific members held } \\
\text { accountable for individual components }\end{array}$ \\
\hline Rewards & Rewards (punishment) limited to one individual & Outcomes shared by all members \\
\hline Effort required & Individual effort & Joint effort \\
\hline Performance achieved & Output is equal to the sum of the individual inputs & Output is greater than the sum of individual inputs \\
\hline Relationship between tasks & Related tasks & Interdependent tasks \\
\hline
\end{tabular}


a functional perspective, teams can be classified into three types (16):

- Teams that recommend things include task forces, project teams, and audit, quality, or safety teams asked to study and solve particular problems.

- Teams that make or do things include people at or near the front lines who are responsible for doing the basic manufacturing, development, operations, marketing, sales service, and other value-adding activities of a business.

- Teams that run things include managers from the top of the enterprise down through the divisional or functional level.

Other typologies of teams have been identified, some of which overlap in their dimensions. One classification of teams includes work teams, parallel teams, project teams, and management teams (16).

- Work teams: Continuing work units responsible for producing goods or providing services; memberships are typically stable, well defined, and usually full-time (15)

- Parallel teams: Teams that pull together people from different work units or jobs to perform functions that the regular organization is not well equipped to perform, such as safety teams or quality improvement teams (41)

- Project teams: Teams that produce one-time outputs, such as a new product or service to be marketed by the company, a new information system, or a new plant (46)

- Management teams: Teams that coordinate and provide direction to the subunits under their jurisdiction, laterally integrating interdependent subunits across key business processes (51)

Another classification scheme includes problem-solving teams, self-managed teams, and cross-functional teams (59).

- Problem-solving teams: Members share ideas or offer suggestions on how work processes and methods can be improved. However, these teams are rarely given the authority to unilaterally implement any of their suggested actions.

- Self-managed work teams: Groups of employees who take on the responsibilities of collectively planning and scheduling work, controlling the pace of work, making operating decisions, and taking action on problems. Fully self-managed work teams even select their own members and have members evaluate each other's performance.

- Cross-functional teams: Teams made up of employees from about the same hierarchical level but from different work areas, who come together to accomplish a specific task.
Teams can also be classified based on their degree of autonomy (from low to high) in the following five team types (3).

- Traditional work teams: Workers perform core production activities but have no management responsibility or control.

- Quality circles: Members join voluntarily with no financial rewards. The team has the responsibility for making suggestions but does not have the authority to make and implement decisions. The problem-solving domain is limited to quality- and productivity-related issues and cost reduction.

- Semiautonomous work teams: Workers manage and execute major production activities.

- Self-managing teams (or autonomous work teams): Members have control over the management and execution of an entire set of tasks-from the acquisition of raw materials through the transformation process to shipping, including all support activities, such as quality control and maintenance, required to produce a definable product. The product could be a definable part of a production process as well as a completed process.

- Self-designing teams: These have all the characteristics of self-managing teams. In addition, they have control over the design of their teams and decide such issues as what tasks should be done and who should belong to the teams.

\section{Why Define a "Team" So Precisely?}

By defining the term "team" precisely and paying attention to our own business needs as they relate to team attributes, we can make informed decisions about whether we can or should implement teams. Furthermore, a clearly defined notion of what is in fact a team provides a set of expectations for both management and team members. For example, collaboration is an important characteristic of teams and is a major contributor to their performance. If the work unit does not have a high degree of collaboration, then it is not really operating as a team. Thus, management must understand that they must facilitate and provide the resources for a team to collaborate, and the team members must understand that this is how their team should operate.

The definition should guide the structure, purpose, and composition of the teams, as well as the decision of whether to employ them in a particular situation. "But wait," you might be thinking. "Isn't the team the 'thing' in business organizations these days?" Well, it's certainly true that teams are quite popular and that their implementation has produced good results for many businesses (7). However, that does not mean that every organization or every 
department in an organization should implement teams or, if they do, that they should expect the same results.

We should recognize that teams are not for every organization. Nor is it always wise to use them. For one thing, teams are expensive to implement and maintain. Hours of training are usually required before employees are comfortable with each other and able to function effectively and efficiently as a team. This is not to say that teams aren't worth it. Rather, it should remind us to be sure that the use of teams is necessary and that the outcomes are desirable before committing resources for their implementation.

\section{Group Process and Teams}

Now that we know what teams are (and are not), we can take a look at how they go about performing their tasks. Basically, the group process model says that the sum of the individuals' potential plus process gain minus process loss equals group effectiveness (62) (Fig. 18.1). Group processes include communication patterns used by team members when they exchange information and ideas, the techniques and processes they use to develop norms and arrive at decisions, the interaction with and the behavior of the leader, the power dynamics within the team, and the way the team resolves conflicts (59). Recognize that the use of teams generates process loss as well as process gain. Process loss includes such things as the time used for team meetings, the extra time it takes for a group to come to a decision, administrative functions that must be performed when people work in teams, and production loss associated with social loafing. (Social loafing is a phenomenon that occurs when some slack off and let others "carry" them by performing the tasks they themselves should be doing.) Process gains are referred to as synergy. For example, when performing a task that requires diverse skills, such as those found in a laboratory, the quality of the decisions and therefore of the output tends to be better than if the individuals worked alone or independently (59).

The group process model is based on the concept that for teams to be worthwhile, process gain must exceed process loss over the long term. The phrase "over the long term" can be illustrated by the following. A number of team-based organizations with which the authors are familiar have weekly team meetings that last approximately one hour. These weekly meetings take time away from the teams' performing their production responsibilities and thus represent process loss. Therefore, the meeting time spent planning work and figuring out ways to be more productive must result in the teams being more productive by working 39 hours and meeting one hour than by working 40 hours with no meeting. Stated another way, the process loss resulting from having the meetings is more than offset by the process gain resulting from the implementation of the decisions made at the team meetings, thus demonstrating how teams can enhance productivity.

Awareness of the time spent on team meetings provokes the following questions: "Are all of these meetings necessary, and are they productive?" and "What would happen if a weekly meeting was skipped?" The answer to the last question is that if a meeting were skipped one week, production would probably increase by about $2.5 \%$ (the percentage increase from 39 to 40 hours) during that week. By the same token, if meetings were continually missed and if the meetings were productive to begin with, then their omission would lead to problems not getting resolved, fewer suggestions being made, and no suggestions receiving the benefit of refinement by the group. Furthermore, conflicts would smolder and metastasize. Hence, these meetings are looked upon not only as a corrective mechanism for past issues but also as an investment of time for future efficiency and increased effectiveness. That is, while the time used for meetings represents one component of process loss, the results of the meetings will be process gain.

It should also be noted and understood that team meetings do not automatically ensure net process gains. There are numerous guides and techniques for conducting effective meetings, and the details will not be repeated here. However, some general guidelines are in order:

- Have a clear purpose or objective for the meeting. Can the objective be accomplished more efficiently in another format, perhaps by posting information on web page or newsletter?

- Have an agenda and distribute it in advance of the meeting. Be sure that each item on the agenda addresses goals of the meeting.

- Make sure the right people are at the meeting.

- Be sure that all team members understand the format of the meetings. Ample opportunity for input from each member should be provided. Input from those who are more reserved, thoughtful, or introverted should be solicited.

- When action is required, tasks should be assigned, resources allocated, and action items followed up. If this

Figure 18.1 Group process model. doi:10.1128/9781555817282.ch18.f1

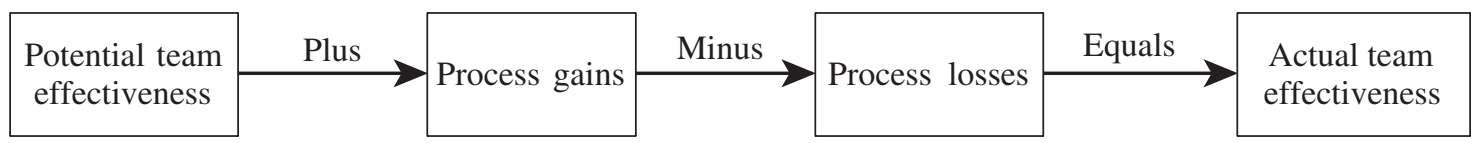


is not done, the message imparted is that the team is not a serious entity and the products and outcomes of the meetings are not important.

For teams to be effective, team members must at times put the team's objectives ahead of their own. For many employees, especially ones new to the organization, this is not a natural behavior and indeed is contrary to what most people are taught. Hence, in some ways, when we ask people to work in a team, we are asking them to do something that is not natural for them. Therefore, anything that would belittle the importance or value of the team in the eyes of the team members should be avoided if at all possible, even if it seems trivial.

\section{Guidelines for Choosing Whether To Have Teams}

Now that we have discussed why an organization would want to have teams, we are in a position to discuss how to determine whether the use of teams is appropriate for given situations and circumstances.

\section{Common Purpose}

One precondition that supports the use of teams is for the teams to have a common purpose. "A common, meaningful purpose sets the tone and aspiration ... inspires both pride and responsibility ... conveys a rich and varied set of meanings to guide what the team needs to do, particularly in meeting its goals ... gives teams an identity that reaches beyond the sum of the individuals involved . . . keeps conflict constructive by providing a meaningful standard against which to resolve clashes between the interests of the individual and interests of the team" (33). A common purpose is not a nebulous, tautological admonition exhorting people to "work together," nor is it a far removed objective such as "corporate profitability." Common purpose, in the context used here, consists of objectives and goals that can only be reached if all members of the team contribute, and the success of a given member's contribution depends upon the success of other members' contributions. Stated another way, a common purpose is one that is unlikely to be achieved without a meaningful and competent contribution from each team member. Teams must not only have a common purpose; all members must understand, accept, and be committed to accomplishing the objectives and goals associated with it (38).

\section{Interdependent Tasks}

By examining the nature of the tasks that must be performed and the relationships among those tasks, we can sometimes reach an understanding of how each member will contribute to the successful accomplishment of the team's purpose. This understanding should help answer another important question: Do the individuals who would make up the team really need to collaborate to accomplish team goals? In particular, we are interested in the degree of interdependence among their tasks. Tasks are interdependent if their progression or completion is influenced by, determined by, or subject to the progression or completion of one another. Stated another way, task interdependence can be thought of as the degree to which the completion of a given task requires that other tasks are completed, the degree to which the given task must be completed for another task to be completed, or the degree to which the individual performing the given task must interact with others to complete the task.

Task interdependence can be thought of as having three types or forms: (i) pooled interdependence, (ii) sequential interdependence, and (iii) reciprocal interdependence (Fig. 18.2). Pooled interdependence occurs when two individuals function with relative independence but their combined output contributes to the group's or organization's overall goals. An example of pooled interdependence would be an assembly shop that has a number of employees, each working alone to assemble radios. At the end of the day, the completed radios are shipped out together. In this case the workers' efforts are independent, but the

Figure 18.2 Types of task interdependence. doi:10.1128/9781555817282.ch18.f2

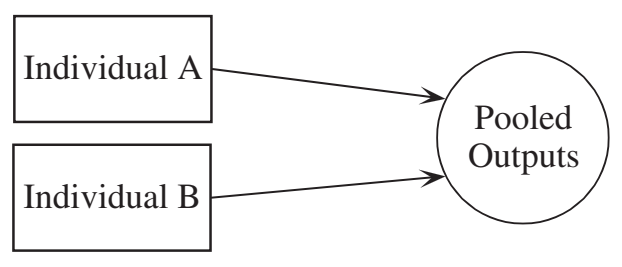

Pooled Interdependence

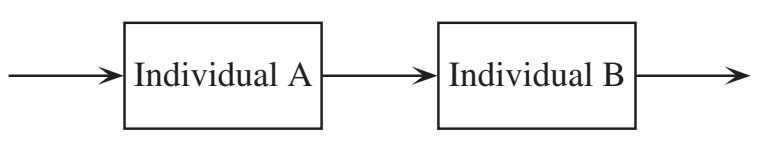

Sequential Interdependence

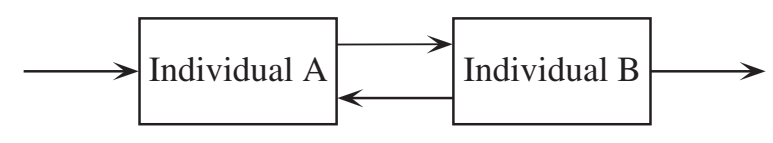

Reciprocal Interdependence 
results of their efforts are pooled, and it could be said that the shop produced $x$ number of radios. An example of pooled interdependence in a laboratory setting would be two technologists independently reading culture plates, one for the aerobic bacterial culture and the other for the anaerobic culture.

Sequential interdependence occurs when workers depend upon others for their inputs. The dependency is in only one direction, and if those who provide the inputs don't perform their jobs properly, those who are dependent on them will be significantly affected. An example of sequential interdependence is an assembly line. In the above radio shop example, sequential interdependence would exist in a case where each worker installed a component in a partially completed radio and passed the partially assembled unit on to the next worker in the line. That worker would then install a component, and so on. The steps have a specific order, and individuals cannot perform their tasks until the tasks that precede theirs are completed. In a laboratory setting an example of sequential interdependence might be specimen accessioning by one individual, specimen processing by a second, and specimen analysis by a third.

Reciprocal interdependence occurs when individuals exchange inputs and outputs. If the performance of any task is compromised, the effect will eventually be visited upon the other tasks. For example, sales people in contact with customers acquire information about the customers' future needs. The sales department relays this information back to the product development department so they can create new products or alter existing ones to meet the described needs. At the same time, the product development department may try to anticipate customers' future needs. By keeping the sales force informed of their innovations, they influence the interactions that sales representatives have with customers. A medical example would be a surgical team wherein the actions of each member influence and are influenced by the actions of the others (33).

It is possible to make rather objective assessments of the type and degree of task interdependence that exists among specific tasks. However, whether the workers who are performing the tasks would agree with the assessment is another matter. Current research indicates that various individuals can perceive the degree of task interdependence of the same set of tasks differently (6). This research also indicates that the level of task interdependence perceived by employees is related to their commitment to their organizations and their work teams. The idea behind this is that as employees perceive their efforts as interdependent with the efforts of others, they become more aware of the contributions they are making to the successful attainment of the organization's goals and to the success of those with whom they are working. According to theory, this heightened awareness should enhance employees' ego involvement with their jobs and cause more positive attitudes toward their organizations and teams $(6,48,52)$. The lesson is that it is important for employees to understand how their tasks contribute to (read: "are interdependent with") the success of others' tasks and what the successful performance of these tasks means to the organization.

\section{Summary}

The use of teams should be considered if (i) a common purpose for the collective can be identified, (ii) the individuals who would make up the team thoroughly understand this purpose and accept it, and (iii) one or more of the goals that must be met to achieve the common purpose can be accomplished only through a collective effort.

\section{A Cautionary Note}

Always keep in mind that teams are not panaceas. Even if it is the right thing to do, even if the teams perform well as independent entities, and even if it appears that the teams' goals are congruent with those of the organization, it does not automatically follow that teams are doing the best for the organization. Typically, effective teams require substantial initial investment to design and develop. The example found in case study 1 in Appendix 18.1 illustrates this.

\section{Selecting Team Members}

Skill requirements for team members can be categorized into three types: (i) technical or functional expertise, (ii) problem-solving and decision-making skills, and (iii) interpersonal skills. While members can possess these skills when the team is formed or develop them after it is in place, team performance will erode without them. Thus, it is important that team members are selected based on either possessing these skills or having a strong aptitude for their development. These three basic skill categories are used to set the criteria for team member selection. In practice, these categories take various forms and degrees, depending on the type of team. For example, one can expect task-related skills for a management team to be drastically different from those for a work team. Similarly, decisionmaking skills and interpersonal skills in those two contexts are also likely to differ to a large extent (33).

While the technical expertise and decision-making skills may differ across teams depending upon their goals, objectives, and methods, the required team-related skills tend to be common among all types of teams. Team-related skills can be further categorized as shown in Table 18.2. New team members can be internally or externally recruited, and the tools that the organization uses to select new team members may differ depending on whether the candidates already work for the organization or come from outside. Internal candidates are those that already work for the organization, and managers have knowledge about their knowledge, skills, and abilities (KSAs), as well as their 
Table 18.2 Knowledge, skill, and ability (KSA) requirements for teamwork ${ }^{a}$

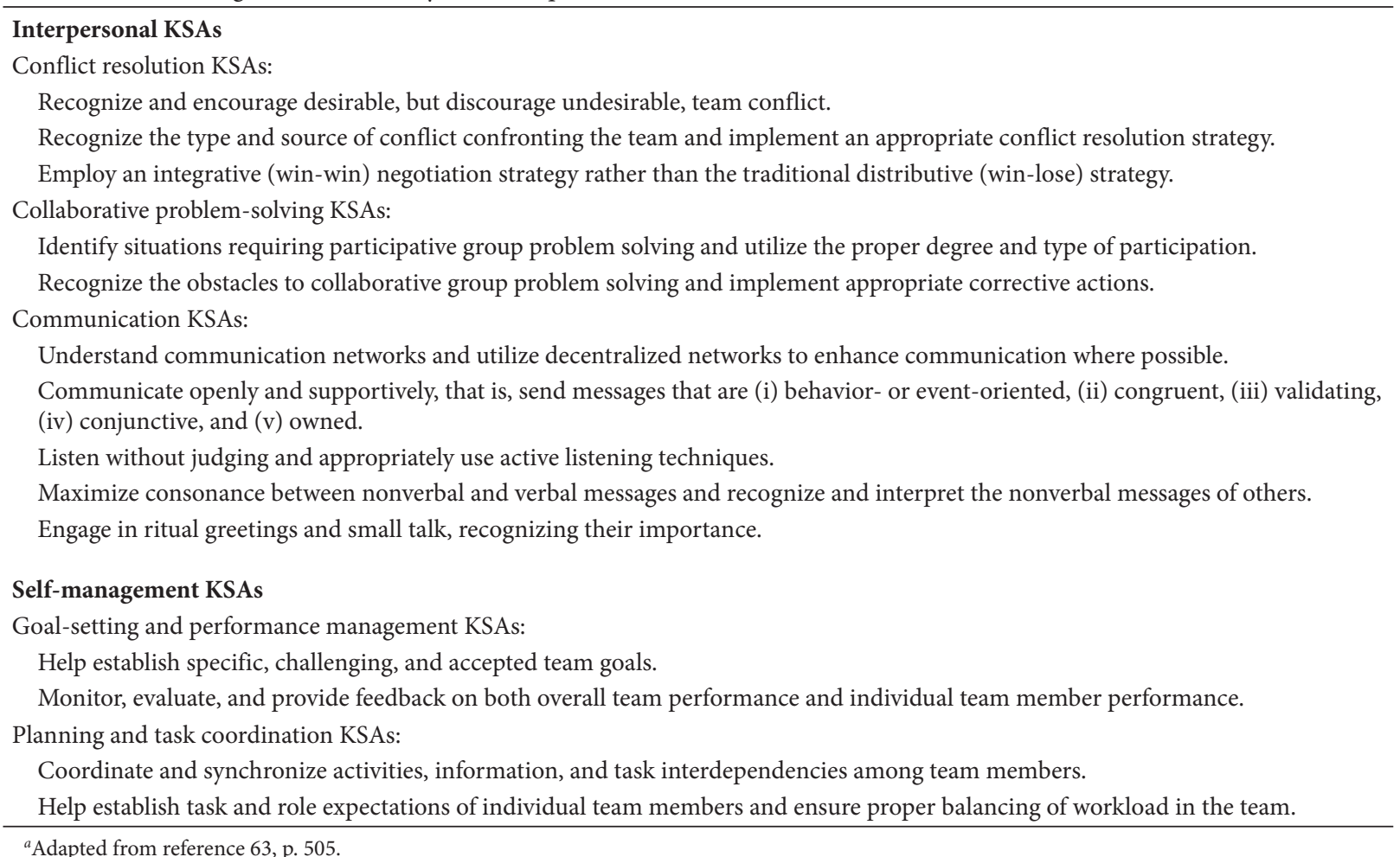

${ }^{a}$ Adapted from reference 63, p. 505.

personality and past performance. Thus, the need for internal candidates to complete a variety of selection tests to gain information may be low compared to external candidates. Sample questions from a selection instrument designed to measure these attributes are shown in Table 18.3.

In addition to written tests, other selection tools can be developed to measure KSAs. For example, structured interviews can be designed to measure whether candidates have adequate levels of these KSAs. Assessment center techniques can be used to measure candidates' leadership and other social skills through group exercises. Biographical data measurement may provide information about candidates' KSAs in dealing with social problems, especially those focusing on experiences candidates had in previous jobs, school, and recreational activities involving teams. One can also integrate team-related KSAs into the recruiting process by communicating the importance of these KSAs through such methods as realistic job previews (63).

The following is an example of how individual traits may affect various attributes of teams, including productivity. In a study of work teams conducted at an apparel factory, certain dispositions of team members were found to be negatively related to team performance or quality. For example, team members who possessed a higher degree of aggression and autonomy were less likely to report high levels of team commitment and team cohesion, two factors often regarded as important antecedents of team performance. In addition, teams were found to have more difficulty in controlling quality when members were talkative or valued extraneous communications among team members at the expense of attention to the team's tasks. Teams with more members willing to use cross-training skills tended to have higher productivity, quality, cohesion, and commitment (60).

In teams, as elsewhere, success breeds success. There is evidence that team members' preferences for teamwork are related to the effectiveness of the team (12). Hence, it is important for teams to experience success early; this starts with member selection. For two examples of team selfselection issues, see case study 2 in Appendix 18.1.

\section{Task-Related Training}

Task-related training focuses on the actual tasks for which the team is responsible. Because of rapidly changing technology, the associated technical skills and knowledge require continuous upgrading. Hence, task-related training is an ongoing process. Training programs should be designed to satisfy the team's need for particular technical skills. Consequently the design should consider each individual member's current abilities, interests, and professional direction. Task-related training can be conducted through formal classroom instruction, on-the-job training, and member-to-member mentoring (56). A variety of e-learning methods are also available, which include 
Table 18.3 Example items from the teamwork-KSA test ${ }^{a}$

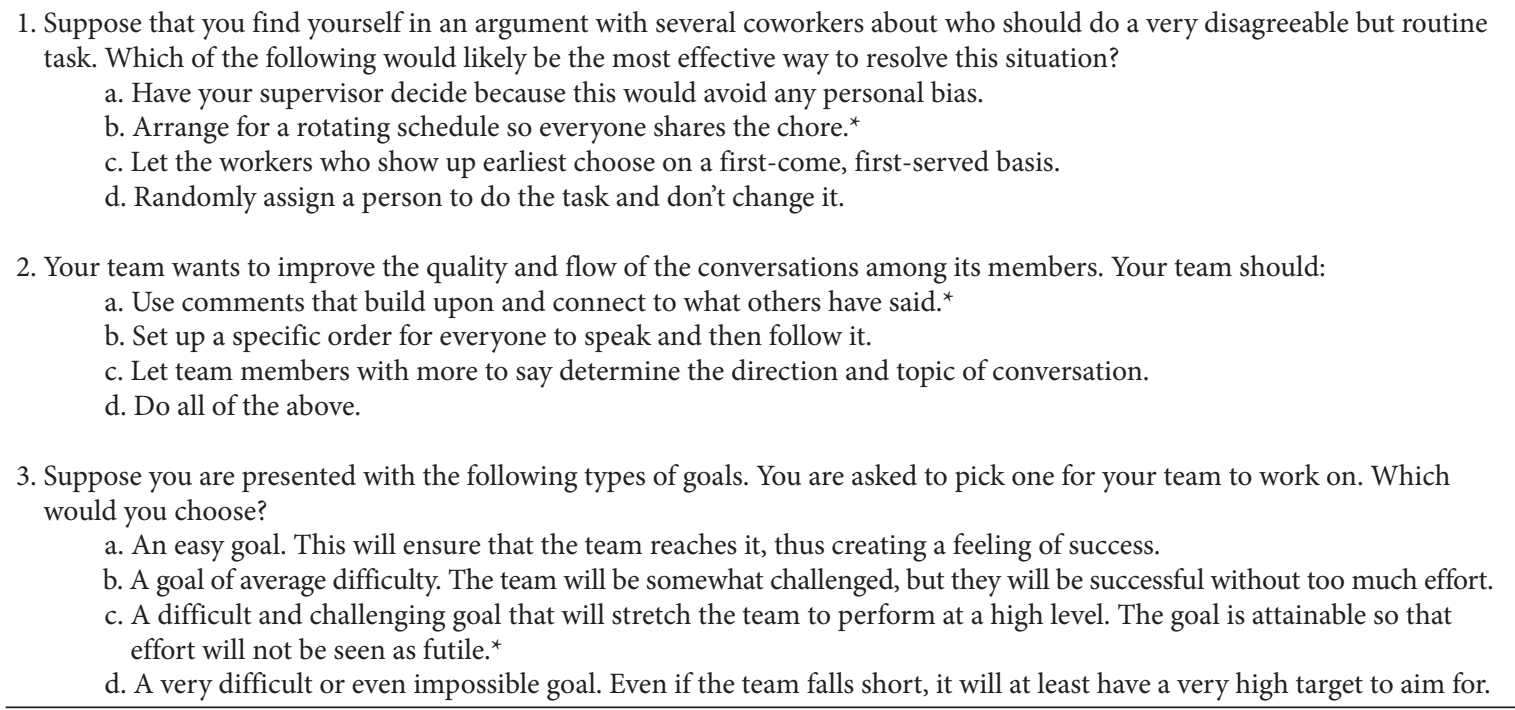

${ }^{a}$ Adapted from reference 63, p. 519. Asterisks indicate correct answers.

webinars, online content, and simulations that allow participants to practice necessary skills.

\section{Team-Related Training}

Research indicates that when team members possess the appropriate team-related KSAs (Table 18.2), there will be positive effects on team performance $(10,18,54,56,63,64$, 69). One of the most important of these skills is the ability to communicate well. Teamwork relies on collective actions and decisions. Furthermore, team members achieve these actions and decisions through exchange of opinions, negotiation, persuasion, compromise, and collaboration. Thus, communication skills and group decision-making skills are essential for collective creation. Training to enhance these skills can start before the work teams are formed and should be made available on an ongoing basis as teams develop and mature.

Numerous authors and consultants have also endorsed team awareness training. The purpose of team awareness training is to give employees an overview of what teams are all about, why the organization is adopting them, and how employees can benefit personally from their team membership (56). Self-managing work teams, and to a lesser degree other types of teams, may take over leadership roles and responsibilities such as scheduling work, safety training, selecting new team members, assigning team members to tasks, and obtaining necessary resources to perform their work.

J. R. Hackman has proposed a four-stage process for creating and developing work teams (Table 18.4). A set of questions associated with each stage can be used to guide

Table 18.4 Guidelines for team building ${ }^{a}$

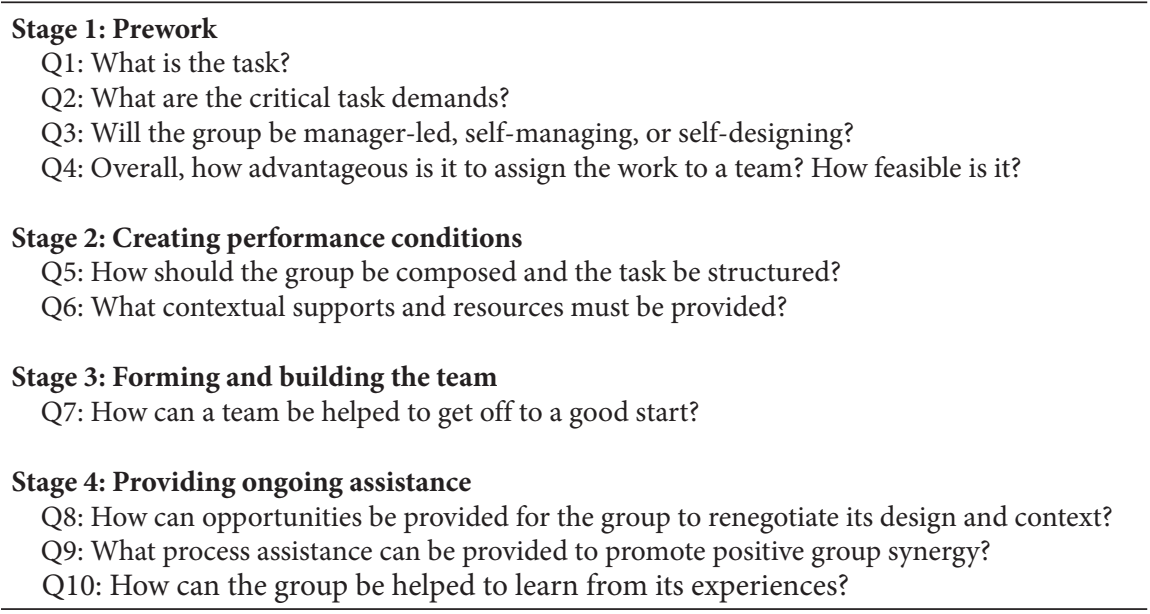

${ }^{a}$ From reference 24, p. 335-337. 
actions. Once these questions are addressed and all four stages are achieved, team members should get substantial return from their effort in terms of work effectiveness and the quality of their interactions with teammates (24). For an example of team-related training, see case study 3 in Appendix 18.1.

\section{Leading Teams}

\section{General Ideas about Leadership: A Brief Review}

Leadership is a process in which one individual exerts influence to structure the behavior of other people within a group (71). Various leadership theories have hypothesized about leadership roles and behaviors, their relationship with group performance, and external conditions that moderate such relationships. Two of the earliest behavioral leadership theories came from studies performed at The Ohio State University and the University of Michigan. The Ohio State study categorized various leadership behaviors into two basic types, labeled "consideration" and "initiating structure." The Michigan study also identified two basic categories of leadership behaviors, labeled "relationship-oriented behaviors" and "task-oriented behaviors." The consideration and relationship-oriented behaviors focus on relationship building and maintenance between leaders and followers. These behaviors have also been referred to as "supportive behaviors" and include acting friendly toward followers, respecting followers' ideas and feelings, appreciating their contributions, recognizing their accomplishments, and showing concern for their welfare and needs.

Both initiating structure and task-oriented behaviors focus on task completion. These include planning, organizing, and scheduling work, planning activities, assigning tasks, coordinating activities, and providing the necessary direction, materials, and support. Initiating structure and task-oriented behaviors have also been termed "directive behaviors" (31). There are numerous other typologies of leadership behaviors, but most tend to be subcategories of the two main categories described above. While there are subtle differences in the definitions of the terms "consideration," "relationship-oriented," and "supportive behavior," as well as the terms "initiating structure," "task-oriented," and "directive behavior," we will not go into that here. For our purposes, we will consider the terms within each category to be synonymous. The Ohio State studies have received the most attention by academics and tend to appear in textbooks more often than the others, though in recent years the terms "directive" and "supportive" have appeared more and more. In any event, we will use the Ohio State designations for the rest of this discussion.

One of the most common errors made by students when first confronted with the two categories of leadership behavior is that they tend to think of "consideration" as good and "initiating structure" as bad. Nothing could be further from the truth, and why students tend to think this remains a mystery to the authors. We suspect they equate consideration with "being nice" and initiating structure with "bossing people around" in an abrasive manner. Such conclusions are erroneous. Each type of behavior has its place, and employees under the right circumstances appreciate each.

For example, when the employee is new, inexperienced, or lacks knowledge or direction, guidance and direction are needed and usually appreciated. This calls for the leader to initiate structure by providing the needed guidance and direction. Employing consideration at such a time would likely be seen as ineffective and evidence that the manager does not understand what is going on. Similarly, initiating structure may be called for if the task is very complex, the situation is ambiguous, or the environment uncertain. Some employees lack confidence, are timid, or have an external locus of control. Individuals with these characteristics may respond well to initiating structure. On the other hand, if the employee is experienced, highly skilled, and particularly competent, then initiating structure may not be needed and may even be resented. Such an employee would respond more positively to the behaviors we have labeled "consideration." Likewise, if the task is simple and generates its own feedback - that is, the employee can easily and quickly see how he or she did and corrective action is easily determined-then consideration is likely to be more appropriate. In such cases, initiating structure would be redundant and ineffective.

Even though these examples may be clear, in the workplace we are often confronted with ambiguous and conflicting situations. For example, what about the situation in which the task is simple (suggesting that initiating structure is not needed) but the employee is inexperienced (suggesting that initiating structure is needed)? In such a case, managerial judgment is required. One alternative might be to ask the employee what he or she needs. Those with an internal locus of control may ask for time to figure it out while those with a more external locus of control may ask for instructions. Take the first individual. Suppose time is of the essence and you don't have time for them to "figure it out." Take the second individual. Suppose figuring things out is a skill they must develop. There are two points here. One is that while managerial education may be a fine thing and while management scholars believe that managerial theory and research are important and helpful, they are not immutable dogma. We must realize that theory, research, and education provide important guidelines to help managers make the tough decisions for which, many times, there are no single "right" answers. The second point is that initiating structure and consideration are not mutually exclusive. Managers can engage in both types of behavior as they are required. It is up to managers to 
apply judgment along with the theories and concepts to the situations they face.

\section{Leadership in a Team Environment}

Performing successfully as a team leader requires a number of skills (34). Successful team leaders know that team performance comes from collective effort and action. An important focus is to motivate team members to support collective performance. To do this, team leaders need to accomplish several objectives. First, "clarify purpose and goals, build commitment and self-confidence, strengthen the team's collective skills and approach, remove externally imposed obstacles, and create opportunities for others" (34). Second, keeping in mind that team success depends on the combined contributions of all members of the team, team leaders should, as much as possible, involve team members in decisions that affect the team and its performance. This approach helps keep members "in the game" and gives them an additional stake in team outcomes. To this end, team leaders should consciously avoid any action that might threaten the desire of team members to make contributions. For example, team leaders should avoid ridiculing or harshly criticizing members' ideas and opinions. Third, it is the team leader's role to develop and facilitate team members, not just control them. Consonant with this objective, leaders must decide upon the amount of autonomy given to members, when to make decisions alone or with the team, and how much responsibility to give inexperienced members: too much and they may fail and hurt the team's performance and their own development; too little and they may never develop, develop too slowly, or become discouraged.

Team leaders can take on other roles. For example, they can be (i) liaisons between the team and other parts of the organization or even other organizations; (ii) resource providers, assisting the team in defining their resource needs and helping to secure those resources; (iii) counselors, helping team members develop problem-solving skills; (iv) mentors, guiding team members to develop organizational savvy; (v) teachers, passing on technical information to team members; or (vi) devil's advocates, challenging the team process of decision making, interpersonal relationships, and progress toward the team's goal (2). Team leaders may also be working members of the team, performing team-related tasks within the purview of the team.

Team leaders and members should be aware that the leader's role may change with the growth of the team (13). Team leaders should also guide members to lead themselves. To do this, some management scholars suggest the following seven steps:

1. Become an effective self-leader. (For further discussion of self-leadership, see reference 47.)

2. Model self-leadership for team members.

3. Encourage team members to set their own goals.
4. Encourage a positive work environment.

5. Reward self-leadership and promote constructive critical feedback.

6. Promote self-leading teamwork.

7. Facilitate a self-leadership culture (47).

\section{Team Leader Selection}

There are a number of ways to select a team leader. The leader can be assigned externally, be elected internally, emerge naturally, or be rotated among team members. Different methods of leader selection have different effects on the leader's legitimacy-how followers perceive the leader's source of authority and respond to the leader. Electing the team leader makes it more likely that the followers will identify with the leader, have more sense of responsibility to the leader, and perceive a greater investment in him or her (28). However, elected leaders will be more likely to face criticism from followers for performance failure (29). Research has shown that teams whose leaders were elected by team members performed better than teams with no leader or teams whose leaders were appointed (22) and that, when compared to appointed leaders, elected leaders received higher ratings from the members on responsiveness to members' needs, interest in the group task, and competence (5).

A naturally emergent leader can be expected to receive similar responses from team members as an elected leader. In both selection processes, team members evaluate the potential leader to determine if the individual possesses the appropriate qualities of a team leader. The difference in the processes is the timing of the evaluation, because with elected leaders potential leader candidates are evaluated before work begins on the group assignments rather than over the course of the project as happens with naturally emergent leaders. However, when leaders emerge on their own, they may shift the team's direction depending on the immediate task and goal. This may not be amenable to the smooth and timely achievement of the organization's and team's goals. There are other dangers in waiting for a team leader to emerge. First, unless the team's production norms are clear and high, an emergent leader may lead the team away from the purpose for which the team was formed. Second, two or more rival leaders may begin to emerge and coalitions may form around them and split the team. Finally, a leader may not emerge or may take too long to do so.

Rotating leaders is another way to generate and maintain team-leading function. In certain self-directed teams, team members rotate the position of team leader. Here, the focus is on the function of the leader position rather than who the team leader is. Rotating leaders tends to work when the task is clearly defined and the direction, vision, and purpose of the team are well understood and do not depend upon who the leader is. This is also an excellent way to give leadership experience to the team members and encourage each member to buy in to the team's purpose. 
Another approach for team leader selection is through a process in which both upper management and the team members participate. Participative selection, if properly structured and guided, can have at least four positive results:

- Selecting high-quality leaders

- Engendering high levels of participant satisfaction

- Fostering better understanding of the leader's job

- Creating positive expectations that enhance the chances of the leader's success through the process of self-fulfilling prophecy (53)

\section{Motivating Team Performance}

\section{Goal Setting and Performance}

One of the most viable and successful motivational techniques to appear in the management literature is goal setting. Goal-setting theories suggest that goals can improve performance because they generate, direct, and sustain effort (43). For goals to have the most positive effect, they should be specific, rather than general or vague; difficult but attainable, rather than easy; and accepted by the team. Attempts to reach them should be accompanied by feedback $(19,43,44,66)$.

General or vague goals, such as "do your best," do not result in the levels of performance that occur when goals are specific, e.g., "increase production by $10 \%$." The specificity of the goal acts as a guide and stimulus, allowing employees to make reasonable inferences about the effort and resources that will be required to obtain the goal. Difficult goals, when met, obviously result in greater performance than corresponding easy goals. However, simply setting difficult goals is not automatically effective. Workers must see the goal as attainable. If the goal is unreasonably high and perceived as unattainable, it may discourage effort rather than motivate it. At the same time, a goal must be accepted by those who will strive to attain it. If a goal is not accepted, individuals are unlikely to strive very hard to reach it.

From this discussion, we might infer that less difficult goals are more likely to be accepted than more difficult ones. However, more difficult goals can be associated with greater rewards, extrinsically as well as intrinsically. Managers who set goals for their employees walk a fine line between setting goals so high as to discourage effort and setting them so low that good performance is not attained. Therefore, managers would do well to ensure that goals are accepted and, to the degree possible, implement a reward structure to support their attainment. This means that leaders must be knowledgeable both in terms of the difficulty of the work and the capability of the team.

Researchers disagree over the usefulness of having employees set their own goals or participate in setting them versus having goals be assigned by management. One school of thought is that employees will try harder if they have the opportunity to participate in setting their own goals. The other school holds that it doesn't matter. The results of research on this question are mixed (40), with participative goal setting being superior in some cases and assigned goals being superior in others. Current thinking is that what matters is that the goal be accepted regardless of how it was set. Therefore, a major advantage of employee participation is the acceptance of the goal.

The final dimension in goal-setting theory is feedback. When people have accepted a goal and are striving to achieve it, they need to know how they are doing. This knowledge helps them identify discrepancies between where they are and where they want to be and what they are doing versus what they should be doing. In effect, feedback acts as a guide for behavior. Research indicates that self-generated feedback is a more powerful motivator than externally generated feedback. In other words, if employees can monitor their own progress, results tend to be better than if they cannot (32).

\section{Goal Setting and Teams}

The performance-enhancing effect of goal setting has been found not only at the individual level but also at the group level $(11,36,43,55,57,58,67,68)$. The results of research with groups parallel those obtained with individuals in terms of goal specificity (55), difficulty (67), attainability (38), acceptance, and feedback (63). Conversely, team effectiveness can be lowered because of a lack of unity or clarity about goals (63). Furthermore, improper assessment of goal difficulty leads to team failure $(37,72)$.

As with individuals, team goals can be assigned or participatively set. Which technique to use depends on the type of team and the tasks the team is assigned. Studies show that participatively setting goals is likely to enhance the acceptance of goals by team members $(49,57)$, increase congruence between individual and team goals $(20,45)$, lead to better-quality goals and satisfaction with the process (42), and increase the likelihood of producing positive outcomes (55). Another possible benefit of team members participating in goal setting is the cohesiveness that can be generated by such interaction. Further, as teams discuss various goal levels, individual members become aware of their teammates' strengths, weaknesses, and overall capabilities. This awareness should assist members in making sound and realistic judgments concerning the team's capabilities as a unit. Frank discussions of member roles in achieving team goals should increase the knowledge of how and to what degree the various tasks are interdependent. As was mentioned before, heightened perceptions of task interdependence are associated with increased organizational and team commitment (6).

\section{Evaluating Teams and Team Members}

Performance evaluation gives feedback to the team and should be used to guide the team in making any adjustment that may be needed (23). Teams need to be evaluated 
as units. A team's achievement can be evaluated based on (i) the degree to which the results that a team delivers are acceptable to those who receive them, (ii) the team being able to work effectively together in the future, and (iii) individual members being more satisfied than frustrated in achieving their personal goals (25).

When the collective outcome (team performance) is assessed, individual team members' contributions must be evaluated as well (65). Different individuals may make disproportionate contributions. In general, this should be avoided. At the same time, the nature of a given team may be that one individual (or a subset of individuals) is simply more capable than the others. In such cases, others may respond by relieving that individual of some of the administrative or "housekeeping" duties and supporting him or her in other ways. Even so, it is important to monitor individual performance so as to prevent social loafing $(1,27$, $35,39,49)$. Most of the time, a team's visible outcome is the result of a collective effort. Consequently, evaluation of individual team members can be problematic. Some experts suggest creating a behavioral instrument based on the sample KSAs for teamwork as displayed in Table 18.3. Honest and constructive peer evaluation is also important.

\section{Pros and Cons of Rewarding Team Members}

Some managers with whom the authors are familiar have suggested giving rewards to individuals who exhibit outstanding performance on a team. In general, we discourage such action. In fact, there are times when it can be counterproductive. For example, when teams are new and have been recently introduced in an organization, there may be a tendency by individuals to resist sacrificing their own autonomy for the sake of the team. To offer individual rewards during this time would, in our view, undermine the team concept and the idea of subordinating individual goals for team goals. For teams to prosper, especially during the initial stages of their formation, we suggest that all rewards be at the team level and all recognitions be for team results. Later, individual rewards may be appropriate, but this action should be carefully considered and done with extreme caution.

\section{Virtual Teams}

Virtual teams are characterized by members who are typically geographically dispersed and communicate primarily through electronic media including email, telephone, texting, video-conferencing, webinars, etc. (17). Virtual teams are quickly moving to the forefront as an organizing strategy as business becomes more global, employees work from remote locations, and travel costs increase. Their use has been facilitated by the expansion of electronic media such as phones, webinars, emails, video conferencing, Skype, texting, and social media.
However, the use of virtual teams can create challenges for organizations and the individuals serving on those teams. Virtual teams can make employees feel increasingly isolated, increase chances of misunderstanding among team members, and create conflicts. Members of virtual teams are also likely to have individual responsibilities in addition to their team assignments or be members of more than one team. Furthermore, virtual exchanges may be less productive because members may attempt to multitask during meetings when they cannot be observed. To minimize the potential problems of virtual teams and take advantage of their positive attributes, we suggest that managers:

- Conduct an initial face-to-face meeting so that team members can get to know the people with whom they will work and can subsequently visualize that person when they are working remotely. When possible, have team members meet in person on occasion throughout the life of the team.

- Use multiple forms of electronic communications to liven up exchanges and encourage individuals to communicate information in different ways depending on what information needs to be shared, work done, or decisions made.

- Make sure that team members have access to all forms of electronic devices that will be used and are comfortable using them.

- Keep in mind that members of the team may be in different time zones or working under different schedules when virtual meetings are scheduled.

In today's world, most teams have a virtual element to them. Other than teams that show up each day to work on a physical product, most teams interact to some extent using some form of electronic medium. Probably we should think about the degree to which teams operate virtually and focus on creating the right balance between virtual and face-to-face interaction.

\section{Global Teams}

Globalization has transformed how business is conducted. A survey of global managers indicated that most of their time was spent working with global teams, and two-thirds of the sample said that they were on multiple global teams (50). Companies "go global" for a number of reasons, including to (i) reach new markets, (ii) realize labor savings, (iii) access cheaper raw materials, and (iv) realize supply chain advantages. Hence, global companies should not be thought of as a set of stand-alone organizations across the globe, but as integrated operations designed to obtain the value of being an effective and efficient global entity.

Global teams deal with issues that transcend countries and the cultures in which any single operation is imbedded. 
Members of global teams may have to communicate using languages in which they are not fluent and interact with people from different cultures who have different mental models of how to approach problems, make decisions, interact with others, and handle conflict (61).

Given the nature and challenges faced by global teams, more time and resources must be invested for them to be effective. First, consideration must be given to the characteristics of the individuals who are placed on global teams. Successful global team members must have language, technical, and social skills as well as an understanding of how to work with those who operate in different cultures. Second, getting a global team together face to face is important, especially when the team is being formed. This is expensive both in time and money. The team's goals and objectives, as well as how the team will work together, should be discussed at the face-to-face meeting. Time should also be allocated for the team members to get to know one another as individuals. Third, local issues and obligations often trump global responsibilities. Clear goals, work structure, and performance criteria must be established. Again, note that responsibility for meeting performance goals may be defined differently by people from other cultures. For example, in some cultures a deadline is absolute, and in other cultures it is fluid. These differences must be discussed up front since these kinds of differences tend to upset people and damage relationships between teammates when encountered while working on a task. Finally, one must allow for misunderstandings and complications.

Common elements of effective teams are trust and commitment among members. One must recognize that distance and culture can be significant barriers for building trust and commitment, and thus members of international teams need to put forth extra effort to ensure a successful and effective team. Furthermore, one can even argue that teams within a diverse country like the United States offer similar challenges as when people from different cultures work together.

\section{Summary}

The use of teams is not easy, and it is certainly not free. In fact, using teams can have important and salient drawbacks. Such drawbacks must be looked upon as investments in the business before teams are implemented. Organizations should be as sure as they can be that their investment in teams will bring forth worthwhile returns. That is, the use of teams should be evaluated just like any other investment.

\section{KEY POINTS}

- The effectiveness of a team can be determined by:

- The acceptability of its results
- The ability of its members to work together in the future

- The value of the team experience to each member

- Conditions that facilitate effective teamwork are:

- A group structure that promotes competent work on the task

- Support and reinforcement of excellence by the organization

- The availability of expert coaching and process assistance

- The essence of a team is a common commitment leading to specific performance goals.

\section{GLOSSARY}

Common purpose A state that is achieved when team members fully understand the team's purpose or reason for existing and there is significant goal congruence.

Gainsharing A financial plan in which improved group productivity determines the amount of money that is shared among the company, investors, and members of the group.

Goal congruence The degree to which team (or group) members' individual goals coincide with the team's (or group's) goals.

Goal setting The process by which team and/or individual goals are determined, communicated, and agreed upon.

Group effectiveness The sum of the group members' individual capabilities, plus process gain, minus process loss.

Group process The way groups get things done, including communication patterns, decision-making methods and techniques, leader behavior and interaction, power dynamics, conflict resolution methods and techniques, and the way members interact with each other.

Leadership legitimacy The degree to which a team or group leader is accepted by both the team or group members and the employing organization.

Participative selection A process in which team members choose new members of their team based on team-related criteria that were determined and agreed upon prior to candidate identification.

Process loss (gain) The degree to which group processes inhibit (enhance) the successful completion of group objectives.

Task interdependence The degree to which a task's progression or completion is influenced by, determined by, or subject to the progression or completion of one or more other tasks.

Work group Two or more individuals who interact primarily to share information and to make decisions that help each other perform within their areas of responsibility.

Work team Two or more individuals whose individual efforts result in a performance that is greater than the sum of those individual parts and who have different tasks but work together adaptively to achieve specified and shared goals. 


\section{REFERENCES}

1. Albanese, R., and D. D. Van Fleet. 1985. Rational behavior in groups: the free-riding tendency. Acad. Manage. Rev. 10:244-255.

2. Aranda, E. K., L. Aranda, and K. Conlon. 1998. Teams: Structure, Process, Culture, and Politics. Prentice Hall, Upper Saddle River, NJ.

3. Banker, R. D., J. M. Field, R. G. Schroeder, and K. K. Sinha. 1996. Impact of work teams on manufacturing performance: a longitudinal field study. Acad. Manage. J. 39:867-890.

4. Batt, R. 2004. Who benefits from teams? Comparing workers, supervisors, and managers. Ind. Relat. 43:183-212.

5. Ben-Yoav, O., E. P. Hollander, and P. J. D. Carnevale. 1983. Leader legitimacy, leader-follower interaction, and followers' ratings of the leader. J. Soc. Psychol. 121:111-115.

6. Bishop, J. W., and D. J. Scott. 2000. An examination of organizational and team commitment in a self-directed team environment. $J$. Appl. Psychol. 85:439-450.

7. Bishop, J. W., K. D. Scott, and S. M. Burroughs. 2000. Support, commitment, and employee outcomes in a team environment. J. Manage. 26:1113-1132.

8. Brandyberry, A. A., and S. A. Bakke. 2006. Mitigating negative behaviors in student project teams: an information technology solution. J. Info. Syst. Educ. 17:195-209.

9. Brannick, M. T., and C. Prince. 1997. An overview of team performance measurement, p. 3-16. In M. T. Brannick, E. Salas, and C. Prince (ed.), Team Performance Assessment and Measurement. Lawrence Erlbaum Associates, Publishers, Mahwah, NJ.

10. Buller, P. F. 1986. The team building task performance relation: some conceptual and methodological refinements. Group Organ. Studies 11:147-168.

11. Buller, P. F., and C. H. Bell. 1986. Effects of team building and goal setting on productivity: a field experiment. Acad. Manage. J. 29:305-328.

12. Campion, M. A., G. J. Medsker, and C. Higgs. 1993. Relations between work group characteristics and efficiency: implications for designing effective work groups. Personnel Psychol. 46:823-850.

13. Carew, D. K., E. Parisi-Carew, and K. H. Blanchard. 1986. Group development and situational leadership: a model for managing groups. Training Dev. J. 40:46-50.

14. Castiglione, J. 2007. Self-managing work teams and their external leadership: a primer for library administrators. Library Manage. 28:379-393.

15. Cohen, S. G. 1991. New approaches to teams and teamwork, p. 194-226. In J. R. Galbraith, E. E. Lawler, and Associates (ed.), Organization for the Future: the New Logic for Managing Complex Organizations. Jossey-Bass, San Francisco, CA.

16. Cohen, S. G., and D. E. Bailey. 1997. What makes teams work: group effectiveness research from the shop floor to the executive suite. J. Manage. 23:239-290.

17. Curseu, P. L., R. Schalk, and I. Wessel. 2007. How do virtual teams process information? A literature review and implications for management. J. Manage. Psychol. 23:628-652.

18. De Meuse, K. P., and S. J. Liebowitz. 1981. An empirical analysis of team-building research. Group Organ. Studies 6:357-378.
19. Earley, P. C., G. B. Northcraft, C. Lee, and T. R. Lituchy. 1990. Impact of process and outcome feedback on the relation of goal setting to task performance. Acad. Manage. J. 33:87-105.

20. Erez, M. 1986. The congruence of goal setting strategies with sociocultural values and its effect on performance. J. Manage. 8(1):83-90.

21. Glassop, L. I. 2002. The organizational benefits of teams. Hum. Relat. 55:225-249.

22. Goldman, M., and L. A. Fraas. 1965. The effects of leader selection on group performance. Sociometry 28:82-88.

23. Goodman, P. S. S., R. Devedas, and T. L. C. Hughson. 1988. Groups and productivity: analyzing the effectiveness of self-managing teams, p. 295-327. In J. P. Campbell and R. J. Campbell (ed.), Productivity in Organizations. Jossey-Bass, San Francisco, CA.

24. Hackman, J. R. 1987. The design of work teams, p. 315-342. In J. W. Lorsch (ed.), Handbook of Organizational Behavior. Prentice Hall, Englewood Cliffs, NJ.

25. Hackman, J. R. 1990. Groups that Work (and Those that Don't): Creating Conditions for Effective Teamwork. Jossey-Bass Publishers, San Francisco, CA.

26. Hansen, R. S. 2006. Benefits and problems with student teams: suggestions for improving team projects. J. Educ. Bus. 82:11-19.

27. Harkins, S. G. 1987. Social loafing and social facilitation. J. Exp. Social Psychol. 23:1-18.

28. Hollander, E. P. 1993. Legitimacy, power, and influence: a perspective on relational features of leadership, p. 29-47. In M. M. Chemers and R. Ayman (ed.), Leadership Theory and Research: Perspectives and Directions. Academic Press, San Diego, CA.

29. Hollander, E. P., and J. W. Julian. 1970. Studies in leader legitimacy, influence, and innovation, p. 33-69. In L. L. Berkowitz (ed.), Advances in Experimental Social Psychology, vol. 5. Academic Press, New York, NY.

30. Hollenbeck, J. R., D. J. Sego, D. R. Ilgen, D. A. Major, J. Hedlund, and J. Phillips. 1997. Team decision-making accuracy under difficult conditions: construct validation of potential manipulations using TIDE simulation, p. 111-136. In M. T. Brannick, E. Salas, and C. Prince (ed.), Team Performance Assessment and Measurement: Theory, Methods, and Applications. Lawrence Erlbaum Associates, Publishers, Mahwah, NJ.

31. Howell, J. P., and D. L. Costeley. 2001. Understanding Behaviors for Effective Leadership. Prentice Hall, Upper Saddle River, NJ.

32. Ivancevich, J. M., and J. T. McMahon. 1982. The effects of goal setting, external feedback, and self-generated feedback on outcome variables: a field experiment. Acad. Manage. J. 25:359-372.

33. Katzenbach, J. R., and D. K. Smith. 1993. The Wisdom of Teams: Creating the High-Performance Organization. Harvard Business School Press, Boston, MA.

34. Katzenbach, J. R., and D. K. Smith. 1993. The discipline of teams. Harv. Bus. Rev. 72:111-120.

35. Kerr, N. L., and S. E. Bruun. 1983. Dispensability of member effort and group motivation losses: free-rider effects. J. Pers. Soc. Psychol. 44:78-94. 
36. Koch, J. L. 1979. Effects of goal specificity and performance feedback to work groups on peer leadership, performance, and attitudes. Hum. Relat. 33:819-840.

37. Kukla, A. 1975. Preferences among impossibly difficult and trivially easy tasks: a revision of Atkinson's theory of choice. J. Pers. Soc. Psychol. 32:338-345.

38. Larson, C. E., and F. M. J. LaFasto. 1989. Teamwork: What Must Go Right/What Can Go Wrong. Sage, Newbury Park, CA.

39. Latane, B., K. Williams, and S. Harkins. 1979. Many hands make light the work: the causes and consequences of social loafing. J. Pers. Soc. Psychol. 37:822-832.

40. Latham, G. P., M. Erez, and E. A. Locke. 1988. Resolving scientific disputes by the joint design of crucial experiments by the antagonists: application to Erez-Latham dispute regarding participation in goal setting. J. Appl. Psychol. 73:753-772.

41. Ledford, G. E., E. E. Lawler, and S. A. Morhman. 1988. The quality circle and its variations, p. 255-294. In J. P. Campbell, R. J. Campbell, and Associates (ed.), Productivity in Organizations. Jossey-Bass, San Francisco, CA.

42. Levine, J. M., and R. L. Moreland. 1990. Progress in small group research. Annu. Rev. Psychol. 41:585-634.

43. Locke, E. A., and G. P. Latham. 1990. A Theory of Goal Setting and Task Performance. Prentice Hall, Englewood Cliffs, NJ.

44. Locke, E. A., K. N. Shaw, L. M. Saari, and G. P. Latham. 1981. Goal setting and task performance. Psychol. Bull. 90:125-152.

45. Mackie, D. M., and G. R. Goethals. 1987. Individual and group goals, p. 144-166. In C. Hendrick (ed.), Review of Personality and Social Psychology. Sage, Beverly Hills, CA.

46. Mankin, D., S. G. Cohen, and T. K. Bikson. 1996. Teams and Technology: Fulfilling the Promise of the New Organization. Harvard Business School Press, Boston, MA.

47. Manz, C. C., C. P. Neck, J. Mancuso, and K. P. Manz. 1997. For Team Members Only: Making Your Workplace Team Productive and Hassle-Free. American Management Association, New York, NY.

48. Mathieu, J. E., and D. M. Zajac. 1990. A review and metaanalysis of the antecedents, correlates, and consequences of organizational commitment. Psychol. Bull. 108:171-194.

49. Matsui, T., T. Kakuyama, and M. U. Onglatco. 1987. Effects of goals and feedback on performance in groups. J. Appl. Psychol. 72:407-415.

50. Maznevski, M. L., and N. A. Athanassiou. 2006. Guest editors' introduction to the focused issue: a new direction for global teams research. Manage. Int. Rev. 46:631-645.

51. Morhman, S. A., S. G. Cohen, and A. M. Morhman. 1995. Designing Team-Based Organizations: New Forms for Knowledge Work. Jossey-Bass, San Francisco, CA.

52. Morris, J. H., and R. M. Steers. 1980. Structural influences on organizational commitment. J. Vocat. Behav. 17:50-57.

53. Newstrom, J., M. Lengnick-Hall, and S. Rubenfeld. 1987. Recruitment: how employees can choose their own bosses. Personnel J. 66:121-126.

54. Nicholas, J. M. 1982. The comparative impact of organization development interventions on hard criteria measures. Acad. Manage. Rev. 7(3):531-542.
55. O'Leary-Kelly, A. M., J. J. Martocchio, and D. D. Frink. 1994. A review of the influence of group goals on group performance. Acad. Manage. J. 37:1285-1301.

56. Orsburn, J. D., L. Moran, E. Musselwhite, and J. H. Zenger. 1990. Self-Directed Work Teams. Business One Irwin, Homewood, IL.

57. Pearson, C. A. L. 1987. Participative goal setting as a strategy for improving performance and job satisfaction: a longitudinal evaluation with railway track maintenance gangs. Hum. Relat. 40:473-488.

58. Pritchard, R. D., S. Jones, P. Roth, K. Steubing, and S. Ekeberg. 1988. Effects of group feedback, goal setting, and incentives on organizational productivity (monograph). J. Appl. Psychol. 73:337-358.

59. Robbins, S. P. 1998. Organizational Behavior, 8th ed. Prentice Hall, Upper Saddle River, NJ.

60. Scott, K. D., and A. Townsend. 1994. Teams: why some succeed and others fail. HR Mag. 38:62-67.

61. Stahl, G. K., M. L. Maznevski, A. Voigt, and K. Josnen. 2010. Unraveling the effects of cultural diversity in teams: a meta-analysis of research on multicultural work groups. J. Int. Bus. Stud. 41:690-709.

62. Steiner, I. D. 1972. Group Process and Productivity. Academic Press, New York, NY.

63. Stevens, M. J., and M. A. Campion. 1994. The knowledge, skill, and ability requirements for teamwork: implications for human resource management. J. Manage. 20:503-530.

64. Tannenbaum, S. I., R. L. Beard, and E. Salas. 1992. Team building and its influence on team effectiveness: an examination of conceptual and empirical developments, p. 117-153. In K. Kelley (ed.), Issues, Theory, and Research in Industrial and Organizational Psychology. Elsevier, Amsterdam, The Netherlands.

65. Tesluk, P., J. E. Mathieu, and S. J. Zaccaro. 1997. Task and aggregation issues in the analysis and assessment of team performance, p. 197-224. In M. T. Brannnick, E. Salas, and C. Prince (ed.), Team Performance Assessment and Measurement. Lawrence Erlbaum Associates, Publishers, Mahwah, NJ.

66. Tubbs, M. E. 1986. Goal setting: a meta-analytic examination of the empirical evidence. J. Appl. Psychol. 71:474-483.

67. Weingart, L. R. 1992. Impact of group goals, task component complexity, effort, and planning on group performance. J. Appl. Psychol. 77:682-693.

68. Weldon, E., K. A. Jehn, and P. Pradhan. 1991. Processes that mediate the relationship between a group goal and improved group performance. J. Pers. Soc. Psychol. 61:555-569.

69. Woodman, R. W., and J. J. Sherwood. 1980. The role of team development in organizational effectiveness: a critical review. Psychol. Bull. 88:166-186.

70. Yang, S.-B., and M. E. Guy. 2011. The effectiveness of selfmanaged work teams in government organizations. J. Bus. Psychol. 26:531-541.

71. Yukl, G. 1998. Leadership in Organizations, 4th ed. Prentice Hall, Upper Saddle River, NJ.

72. Zander, A. F., and T. Newcomb. 1967. Group levels of aspiration in United Fund campaigns. J. Pers. Soc. Psychol. 6:157-162. 


\section{APPENDIX 18.1 Case Studies}

\section{CASE 1: WHEN A GOOD TEAM GOES BAD}

\section{Team Commitment}

(This is a stylized account of an actual situation that occurred in a branch of the armed services in a country that will remain nameless.)

Generally, we think of commitment to one's team and its goals as a precursor to team performance. Certainly team performance is a good thing, isn't it? After all, isn't that what we wish for? However, as the old saying goes, "Be careful what you wish for. You might get it." Consider the following anecdote.

In a branch of the armed services, there was a company of helicopter "flights." Each flight consisted of several helicopters, and the company consisted of several flights. Each flight had a maintenance team, or ground crew, that was responsible for keeping the helicopters in their flight up and running.

In one particular company there was an "all-star" ground crew who, it seemed, never had an inoperable helicopter. Their "birds" were always airworthy. Their success was the stuff of legends and was in sharp contrast to the "up-time" achieved by other flight crews. Though competent and hardworking, the other crews seemed to have one or more of their birds down at any given time. Knowing just this, one would be tempted to say, "The AllStars are really a great team. Clearly their goals and objectives are congruent with the company's goals and objectives. Furthermore, they should serve as a role model for other teams, who should copy their methods."

But do they have goal congruence with the company? Should they serve as a role model for other teams? Let's take a closer look and see.

\section{The Situation}

As those familiar with helicopters can attest, because of the nature of the movable wing aircraft design, helicopters are notorious for wearing out parts. Therefore, a good supply of spare parts is absolutely essential to keep a company of helicopters flying. In addition to their skill and motivation, one of the reasons for the success of the All-Stars was that they never experienced a shortage of spare parts. On the other hand, the other crews were constantly short of parts and even resorted to cannibalizing parts from inoperable helicopters, something the All-Stars never had to do. Why was this? Wasn't there a common store of parts from which the flights drew replacements? Yes. Well then, didn't everyone have the same access to parts? Yes-at least officially. But in reality the truth was quite different.

It turned out that the All-Stars had their own parts procurement process to "supplement" company procedures. They went around the chain of command; they established informal relationships with the appropriate quartermaster personnel, and they devised an extra-official parts procurement process and procedure of their own. As if that wasn't enough, they hoarded parts. Because some helicopter parts wear out in a predictable manner, it was known beforehand which parts would likely be needed in greater quantities. It was these parts that the All-Stars hoarded in the greatest quantity. The result was that although the All-Stars had $100 \%$ up-time for their helicopters, the company as a whole had a number of helicopters down for want of parts that the All-Star team members possessed in abundance.

\section{The Lesson and What To Do}

A major lesson here is that even though the achievement of team goals may appear to coincide with and further organizational goals, the methods of achieving team goals may inhibit or even prevent the achievement of organizational goals.

What should a manager do in such a circumstance? Usually with exercises of this type, students want more information before making a decision. Granted, in such cases it is difficult to know exactly what we would do. Furthermore, we need to keep in mind that this is a military unit and therefore may be subject to military rules and regulations that differ significantly from those in the civilian world.

However, with the information provided, we can articulate some reasonable alternative actions that would be appropriate in the civilian sector. First, it is highly unlikely that the All-Star team could be salvaged as an intact unit. The team norms are too strong and run too much counter to the objectives of the organization. Second, hoarding parts may be grounds for dismissal. At the very least the team should be broken up and the members dispersed throughout the company, or preferably, across several companies (or units in a civilian organization). Similar action would be required with respect to those in the parts supply chain who enabled the All-Stars' shenanigans.

It is easy, though often counterproductive, to point out to people what should have been done. Even so, in this case, what should have been done and what must be done now are much the same. In addition to the actions related to the ground crew team and the parts personnel, the organization must reevaluate its team training program and the components that comprise it. Those responsible for training, as well as company management, must ensure that team objectives include knowledge of organizational objectives and techniques for advancing team goals in such a way as to fulfill and not impede these objectives. Care should be taken to ensure that as team norms develop, team members are aware of, concerned with, and take action for the furtherance of organizational goals.

Though our primary purpose in analyzing this case is to consider the issues related to the implementation and use of teams, other aspects of the situation must not be neglected. It is important to do this to avoid a myopic view that would cause us to become one-dimensional in our problem-solving thought processes.

With this in mind we would recommend that a control system for the distribution and use of parts be put in place and its use mandated and supported by management. Particular care must be taken in the design and implementation of such a system. For example, a charge-back scheme has some characteristics that would help prevent situations like the one exemplified by the All-Stars. Charge-backs would require ground crews to have a financial component for which they must be responsible. 


\section{APPENDIX 18.1 Case Studies (continued)}

On the other hand, if the charge-back scheme includes an overly restrictive budget or if rewards for a parts budget surplus are emphasized, then teams may be motivated to skimp on the use of parts and try to stretch the usable life of the parts too far-with disastrous consequences.

\section{Summary}

Team goals did coincide with organization goals, but the methods of achieving the team goals inhibited the achievement of organizational goals.

\section{CASE 2: TWO EXAMPLES OF HOW AND HOW NOT TO SELECT TEAM MEMBERS}

Example 1: Selecting New Members for Established Teams (an Automotive Outsourcing Plant)

Invariably, the composition of teams will change over time. Members quit or get fired, promoted, or transferred. When a position on a team opens, filling that position presents unique challenges. In addition to the traditional selection criteria involving task-related KSAs, team-related criteria must be considered for a successful match to be made. Some of the additional questions that arise are, "Can the applicant work well in a team environment? Can the applicant work well with the particular team that has the vacancy? Can the team work well with the applicant?"

One organization with which the authors are familiar approached this problem in the following way. First, the human resources department screened the applicants for the traditional KSAs that are required for successful performance on the job in question, checked references, confirmed job histories, and performed the appropriate background checks. Following this screening process, three to five candidates whom the company would hire were presented to the team. The team members reviewed the documentation gathered by the human resources department and, considering this information in light of the team's requirements, interviewed the candidates for the purpose of making the final selection. The candidates interviewed with the team members individually and as a group. Team members were trained in structured and unstructured interviews. They were fully aware that their purpose was twofold. One, they were trying to sell their team to the candidate and, two, they were trying to determine if the applicant would make a good teammate.

This system seemed to produce sufficient initial commitment between the chosen new member and the established team; after all, they chose each other. These initial positive feelings can be enhanced or squandered depending upon subsequent actions by the parties involved. But at least it's a positive start, and the system worked well for this organization and its employees.

\section{Example 2: Selecting Members for Newly Formed Teams (a Sewing Plant)}

The previous example illustrated a reasonable and effective method of selecting replacement members for existing teamsteams that are up and running. We now turn our attention to an example of a method for selecting team members when teams are first implemented in an organization. In this instance, the organization was the owner of more than a dozen sewing plants, both in the United States and overseas. Management made the decision to go from individual sewing to team sewing. The individual sewing method involved tasks that were characterized by sequential interdependence. Individual sewers performed their tasks on partially completed garments before they were passed on to other stations where other tasks were performed. Each individual was responsible for his or her own task and no other. Compensation was based on piecework.

In the team method the tasks had characteristics of both sequential and reciprocal interdependence. Compensation was still based on piecework but at the team level, that is, everyone on the team was compensated at the same rate for what the team produced. The objectives for implementing teams included cutting costs by reducing work-in-process inventory; reducing turnaround time between customers' orders and the organization's delivery; improving quality by reducing dirt, oil, and grease; and achieving a more flexible workforce by crosstraining employees and having them be collectively responsible for results. Employees received task-related and team-related training. The latter included communication skills development, conflict resolution and problem-solving techniques, and other group process training.

Because there were no teams already in place, team member selection meant choosing all members of all teams, not filling an opening on an existing team. This called for the organization to employ a different selection strategy as contrasted with the one described in the previous example. For one thing, the employees were already working for the company. Therefore, initial screening was not required. For another, teams were new in the work environment and required that the employees work in a significantly different way. Consequently, management rightly anticipated some resistance to the change. To reduce resistance, increase employees' acceptance of the team concept, and promote psychological ownership of employees' teams, management concluded that the employees should form their own teams, in their own way, with their own selection criteria. Note that the formation was done after initial training was given in team-related skills.

Management predicted that employees would choose their teams based on friendships and kinship. Management also believed that this initial attempt would most likely fail. Even so, management was willing to accept this initial setback to allow employees the decision-making authority it believed would, in the long run, enhance employee buy-in to the team concept and obviate some of the initial resistance. Management also felt it was better not to be in the position of forcing people to work together.

Management was right on both of their predictions. First, teams initially consisted of friends and relatives; the employees' selection criteria focused on these attributes and tended to ignore other, more task-related, ones. Second, the teams soon failed. The team strategy was not halted because management's assessment was that the use of teams was not an option but a necessity based on the competitive environment. Hence, the teams were reformed. 


\section{APPENDIX 18.1 Case Studies (continued)}

When the teams were formed the second time, selection was again left to the employees' discretion. Only this time, on their own, the employees used different selection criteria. This time, the ability to sew at a similar speed as others who would make up the team and the desire to make the same amount of money were the top criteria. This meant that team members shared the same goal and possessed the same means to achieve it. It should be noted that just because the initial teams were composed of friends and family, this was not the problem. In fact, when friends and family members possessed similar skill levels and shared the same monetary goals, their teams worked quite well.

This example illustrates the importance of shared goals and the collective means of achieving them. In no way does this illustration negate the importance of personal compatibility within teams. Rather, it illustrates that while personal compatibility may be important for team success, it does not constitute a sufficient condition. Further, personal compatibility can be enhanced when members possess common goals and the means to achieve them.

CASE 3: TEAM-BUILDING EXERCISES: AN EXAMPLE

A number of exercises are frequently used for team building and to train individuals in group process skills. One of the more popular exercises involves having the trainees rank a list of objects in a survival situation. There are numerous survival scenarios, including being stranded in the Artic, in the desert, on the moon, in a lifeboat, and in the wilderness where it's hot, cold, wet, or excessively dry. Trainees are asked to come up with their rankings of the items based on the situation. First they do so individually and then as a group. The group must reach a consensus and produce a single ranking. Both the individual and group rankings are scored against experts' rankings. Difference scores for the individuals and the group are computed. The individuals' difference scores are averaged; this represents the team potential without considering process gain and process loss. This average is subtracted from the group's score; the difference represents one component of the process gain (positive number) or process loss (negative number). Usually, but not always, the team's score is superior to the average of the individuals' scores, indicating a process gain in accuracy by the group over the individuals. Invariably, the groups take longer than the individuals to complete this task. This added time represents one component of process loss. Changes in members' knowledge about each other and their preference for working together can represent either process gain or process loss, depending upon whether team members perceive the knowledge they gain about each other to be positive or negative and if their preference for working together in the future is increased (process gain) or decreased (process loss).

Such exercises must have several characteristics to work. First, the solution to the problem must require knowledge that is not generally known to the trainees. If the solution to the problem is well known, then no problem solving will be required by the group. Hence, group discussion, compromise, give and take, trade-offs, and conflict resolution will not be required. Second, the objects that are on the list should be items with which most people have some familiarity. Third, while the environment described in the exercise can be a place or situation with which the trainees are not intimately familiar, it must at least be recognizable in terms of some of its more unique and salient features. These last two points are important because they move the problemsolving techniques employed by the teams toward the application of logical deductions and away from simple guesswork.

Such exercises are designed to show the trainees that teams can make superior decisions when a variety of experiences, viewpoints, and perspectives are brought to bear on a problem. They should also illustrate that team decisions require more time than individual decisions. The trainees should also realize that there are a variety of communication styles and techniques, and the level of communication skills varies from person to person. Trainees should gain insight into their own communication styles as they interact with others to perform a task. These insights should form a base for trainees to evaluate their own and others' styles of working in a team environment and ready them for further training to become productive team members. 


\section{APPENDIX 18.2 Representative Websites ${ }^{a}$}

\section{National Association for Healthcare Quality}

http://www.nahq.org

Publications related to quality healthcare, including team building

Training Services On Demand

http://www.tsod.com/team_building/teambuilding_books.htm

Work teams, team building, and total quality

BusinessTrainingMedia.com Inc.

http://www.business-marketing.com/ or email sales@business

-marketing.com

Videos and training packages, including teams and team building

\section{Clinical Laboratory Management Association} www.CLMA.org

Links to relevant government agencies, other organizations, and other resources; excellent resource

${ }^{a}$ Verified July 14, 2012. 